\title{
Continually Proving Devotion?
}

\author{
Continuing professional development might be one of those conspiracy theories. \\ Stephen Hancocks reassuringly lifts the lid on living with lifelong learning.
}

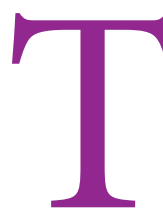

he 'they' who make us do 'things' - like the tiresome impositions of speed cameras to make us slow down - seem like they are out in force again to ensure that even when we're not paying to be at work, through registration and indemnity cover, we have to be working elsewhere to notch up the requisite CPD hours.

Like lots of things in life that become compulsory, the enforcement usually happens because although the majority of folk are already doing (or not doing) whatever it is - not using the mobile phone while driving, for instance - some idiots just won't be told. The same is true of CPD. The majority of dental team members already read journals, go on courses and keep up-to-date because they see the sense in it. It comes as no surprise then, that those who didn't do it before will try to avoid doing it now and will also attempt to bend all the rules to get it done as quickly, cheaply and with the least effort possible. And then ring their friends, on their mobiles while driving, to tell them how smart they've been.

\section{Multiple choice} questions might be one example.

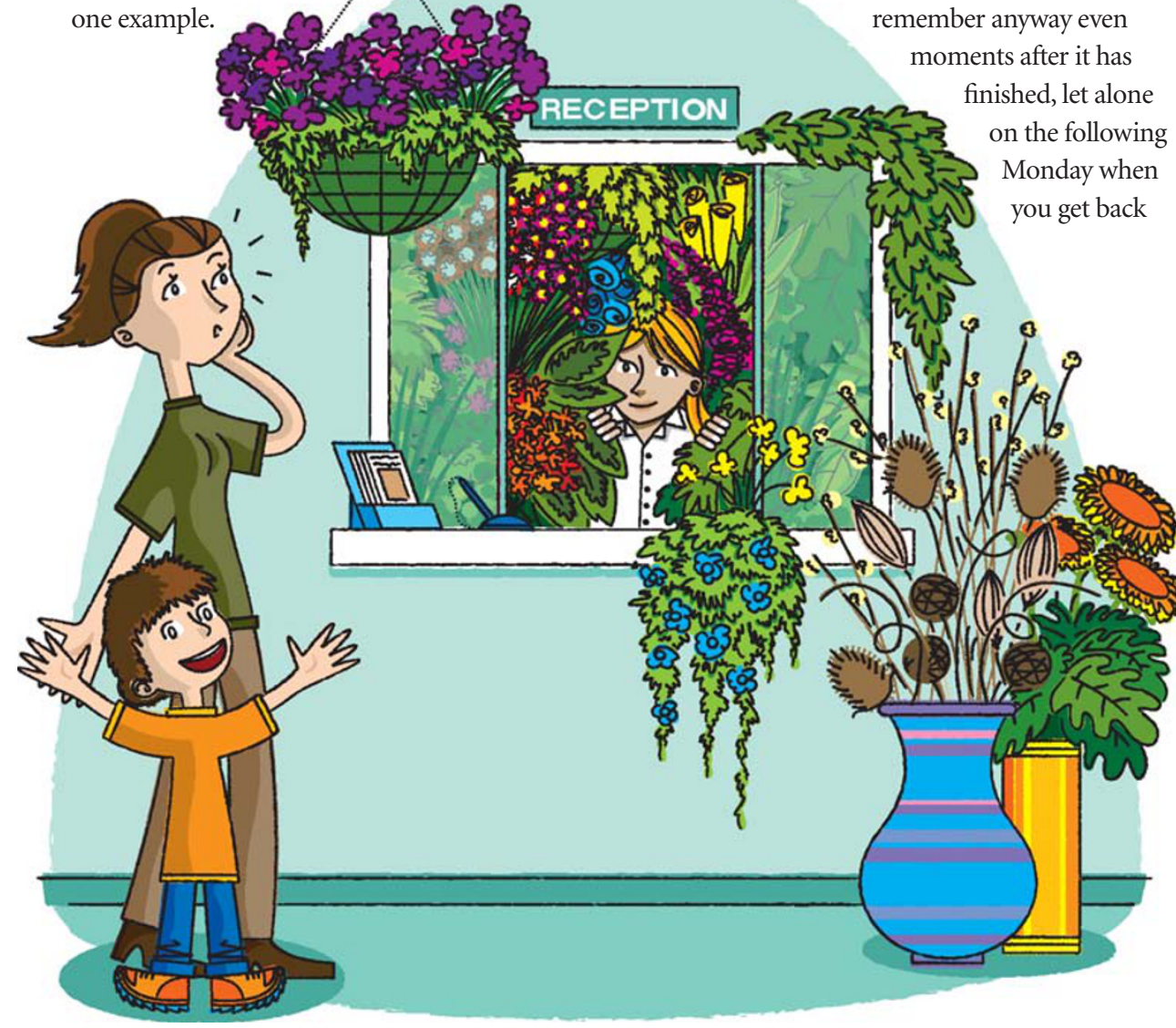

While the diligent amongst us spend time reading the articles, comprehending the questions and making our best attempt at getting them right, the more cavalier allegedly go through ticking at random and have it done in the twinkling of a cowboy's ballpoint. But think back to the bravado school classmates (or not) who sauntered out of the exam hall after a mere three-quarters of an hour of a three hour paper smiling the while and looking back on the rest with a wistful aura of escape. Where are they now?

And there is also the element of boastfulness at play too. How do we know that they merely marked the responses at whim? Chances are they were actually pawing over them for far longer than you or I, so as not to look foolish. Who is going to know? Which is another of the criticisms levelled at CPD: who knows if you spent ten minutes, an entire evening or a week on a particular subject in order to gain a certificate for two hours?

In defending the situation, others point out that it is quite possible to go to a lecture, fall asleep for most of it and still get a certificate. To be really blunt, even if you stay awake, how much of it can you nember anyway even finished let alone to the practice? And here's the rub. Unless we each have our own personal GDC police officer following us around, how is anyone ever going to know if what we've sat through, read, heard, seen or attempted in a workshop has taught us anything. Even if you could prove that, how can it then be shown that if we learnt anything that we then apply it to our daily work? Education, or continuing development is what is says on the tin, a lifelong process of accumulating knowledge and skills. Counting hours is merely a way of attempting to quantify it and bringing to our attention that it needs to be done.

‘...it is quite possible to go to a lecture, fall asleep for most of it and still get a certificate.'

Not that the GDC makes it as simple as it might. There's verified and un-verified, or general, CPD for a given number of hours in a cycle, which is based on a five year period. Half a decade is too long for most of us to comprehend, hence the trick question in interviews 'where do you see yourself being in five years' time?' because if you could answer that you would know whether you'd got the job or not! It is bad enough trying to think about tomorrow's dinner never mind whether or not you've planned your cross-infection control study between now and the opening ceremony of the London Olympics, since August 2012 is when the five year cycle for DCPs who registered last summer comes to an end! Then again, what constitutes relevant study?

Do flower arranging classes in order to make the reception area in the practice look nicer count? Is a core subject to do with apple preparation or was that for my credit crunch-inspired cookery course for beginners?

The message has to be that it will all work out fine in the end. As the system settles down and the hours accumulate so we will all realise that the activity is far from being a conspiracy. Although hang on a minute, what was that about GDC police officers, perhaps they could help me fill in this multiple choice answer form? 